\title{
Editorial
}

\section{Earth Materials and Environmental Applications}

\author{
Zhaohui Li, ${ }^{1,2}$ Hanlie Hong, ${ }^{3}$ and Guocheng Lv ${ }^{1}$ \\ ${ }^{1}$ Beijing Key Laboratory of Materials Utilization of Nonmetallic Minerals and Solid Wastes, National Laboratory of Mineral Materials, \\ School of Materials Science and Technology, China University of Geosciences, 29 Xueyuan Road, Beijing 100083, China \\ ${ }^{2}$ Geosciences Department, University of Wisconsin-Parkside, Kenosha, WI 53144, USA \\ ${ }^{3}$ Faculty of Earth Science, China University of Geosciences, Wuhan 436400, China \\ Correspondence should be addressed to Zhaohui Li; li@uwp.edu
}

Received 22 January 2015; Accepted 22 January 2015

Copyright (C) 2015 Zhaohui Li et al. This is an open access article distributed under the Creative Commons Attribution License, which permits unrestricted use, distribution, and reproduction in any medium, provided the original work is properly cited.

Earth materials refer to the naturally occurring materials including rocks, minerals, and soils. Traditionally, the studies of Earth materials including mineralogy (the study of minerals), petrology (the study of rocks), and pedology (the study of soil) were limited to their occurrence, characterization, and resource utilization. The interactions between Earth materials and anthropogenic compounds (most of them are contaminants) only attracted recent attentions. This is the area that has experienced accelerated research since 1990. Still, due to the use and misuse of emerging compounds (ECs), many are on the targeted watch list and more studies are in great need to explore their fate and transport in the natural environment. In addition to the interactions between of the ECs and Earth materials, development of cost-efficient or energy efficient materials from raw Earth materials for environmental application also picked up recently due to advancement of modern technology. Moreover, studies on mechanical responses of Earth materials to natural and anthropogenic-induced hazards may guide for better structural design and hazard prevention.

In this special issue, we have a collection of 23 papers covering the topics of the following general areas: (1) materials (13 papers), including materials, resources, innovation, and utilization for environmental application, and (2) engineering applications (10 papers), including soils and foundation stabilization and and rhyology improvements.

In the area of materials, the materials innovation studies addressed either new preparation methods of current Earth materials for new environmental applications in contaminant removal and water treatment or new applications in energy transfer processes. A unique method for the synthesis of $\mathrm{BaLa}_{2} \mathrm{ZnO}_{5}: \mathrm{Er}^{3+} / \mathrm{Yb}^{3+}$ was developed and the tunable up-conversion luminescence and energy transfer process between $\mathrm{Yb}^{3+}$ and $\mathrm{Er}^{3+}$ was demonstrated. A $\mathrm{TiO}_{2}-\mathrm{ZrO}_{2}$ composite film with the grain size of $50 \mathrm{~nm}$ was synthesized by electric field and heat treatments and then doped with nitrogen atoms. Photocatalytic experiments using this composite film resulted in significant increase in methylene blue degradation under visible light irradiation.

Simulation using first principle on the structural and electronic properties of nitrogen doped rutile $\mathrm{TiO}_{2}$ of oxygen vacancies showed that the impurity elements do not affect the migration of Fermi level while the conduction band of metal atoms move to the Fermi level, forming the $\mathrm{N}$ type semiconductor material. $\mathrm{A} \mathrm{TiO}_{2}$ /diatomite composite prepared by loading $\mathrm{TiO}_{2}$ on the surface of diatomite resulted in a good photocatalytic enhancement through absorbing organic compounds with diatomite and degrading them by $\mathrm{TiO}_{2}$ and the composite was more active than nano$\mathrm{TiO}_{2}$ for the degradation of methylene blue. For the heavy metal removal side composite cementations materials were prepared with lead-zinc tailings and lead-zinc smelting slag mixed with cement clinker with low lead leaching potential over a large $\mathrm{pH}$ range. To make full use of barite mineral and obtain composite material bearing, the property of both barite and $\mathrm{TiO}_{2}$ was developed by coating barite surface with $\mathrm{TiO}_{2}$ via a solution method and hydrolysis process. The hiding power and oil absorption value of the composite powder were similar to $\mathrm{TiO}_{2}$ alone. In addition to these new solid materials, a new enhanced flocculent based on 
bentonite and formulated with addition of polymeric chloride aluminum, cationic polyacrylamide, ferrous sulfate, and aluminum sulfate was developed for potential application in drinking water in Karamay City, Xinjiang. The treated water reached or exceeded the drinking water standard of China in decolorization and deodorization as well as heavy metal removal.

From materials utilizations studies, several Earth materials were utilized for the removal of contaminants. Uptake of ciprofloxacin on synthesized birnessite was mainly via surface adsorption, instead of cation exchange and quantum mechanics simulation showed that the final energy of the interactions between ciprofloxacin and birnessite was decreased under the condition when the average oxidation states of Mn were lower. Studies on the effect of sintering temperature on membranes performance showed that increases in sintering temperature of the membranes raised the average pores diameter from 0.116 to $0.179 \mu \mathrm{m}$ but decreased the porosity of the membrane from 40.30 to $25.16 \%$, which reduced the water permeated flux for temperatures from 900 to $1100^{\circ} \mathrm{C}$. Studies on interactions between phosphoric/tannic acid and different forms of $\mathrm{FeOOH}$ showed that $3 \%$ tannic acid $+10 \%$ phosphoric acid $+\mathrm{FeOOH}$ was the most suitable formula for rust stabilizer and its reaction products were made up of iron phosphate and chelate of iron and tannin. The results provided optimal combinations for the preservation of iron, especially iron cultural relics. The experimental and simulated breakthrough curves showed that classical colloid filtration theory is able to predict the transport and fate of iron oxide nanoparticles stabilized with PAA up to $500 \mathrm{ppm}$ in a porous media.

As an Earth material or resource, groundwater was evaluated based on Energy theory for Beijing area. In terms of monetary value of groundwater in Beijing, it was 7.64, 6.00, and 3.25 billion Yuan, accounting for $45.24 \%$, 35.52\%, and $19.24 \%$ of the total value, respectively. Based on the data from 2007 input-output tables for each province in China, energy embodied in China's interprovincial trade through input-output analysis was estimated. The results showed that a sizable transfer of energy from the central and western provinces to the eastern and coastal provinces is embodied in China's interprovincial trade.

In the area of environmental application on stabilities of soil and foundations, the rock-soil aggregate sampled from the deep layer of sliding mass at Jinpingzi area of Wudongde hydropower plant on Yangtze River was investigated for its mechanical behavior. Results from large-scale laboratory triaxial tests show that variation of stone content and gradation affected the mechanical characteristics of rocksoil aggregate considerably. Results of studies on hydraulic fracture propagation characteristics in glutenite formation by a series of servocontrolled triaxial large-scale fracturing experiments showed that the fractures extended along the gravel and sandstone cementing face, the extension pressure was fluctuating, and the degree of fluctuation was more drastic with the gravel diameter increase in the process of the fracture extension. An orthogonal study on low-strength similar materials comprising sand, fly ash, and plaster and the sensitivity analyses suggested that their compression strength and elastic modulus decreased as the sand-binder ratio or cement ratio increases. Numerical experiments of biaxial compression using the granular discrete element method were performed in the macro- and microparametric analyses to study the influences of strength of the cementation as affected by the sizes of stone blocks and the content of stone blocks on the peak compressive and shear strength. The seismic response of retaining wall in the Wenchuan earthquake was tested on large shaking table and an acceleration record was acted in 3 directions. The results showed that the dynamic earth pressure increases with the increase of ground shaking from $0.1 \mathrm{~g}$ to $0.9 \mathrm{~g}$ and the relationship is nonlinear. A glass-like casing was developed to mend the instable borehole due to its great similarities in compositions and structure. Different wt $\%$ aluminum and quartz sand were added into the composition, in order to boost the casing's mechanical properties and lower its cost. Investigation of coal/rock intermixing, cracking and crushing of WC grains, and adhesion of rock particles suggested that coal/rock materials penetrate the cracks of the coal cutting tools to enter inside the base material and degrade it. An introduction of a modifier OTAC- $\mathrm{KCl}$ at a combination of ameliorant $0.3 \%$ STAC and $3 \% \mathrm{KCl}$ improved the wetting and drying cycles on engineering properties of expansive soil after 14-day curing time, while the untreated soil specimens collapsed when they were immersed in water.

Finally, studies on coagulation behavior showed that cationic polymer, hydroxy aluminum, and clay minerals are three flocculants with different action mechanisms and a more cost-efficient multiple flocculent could be prepared by compositing them through appropriate technology. The viscosity of an aqueous palygorskite suspension could be increased via physical and chemical processing and the contribution of $\mathrm{MgO}$ to viscosity caused the reinforcing of flocculation and, in drilling applications, the higher viscosity value would provide better cutting suspension and carrying capacity.

\section{Acknowledgments}

We would like to thank all the authors who have submitted their papers to this special issue and also to all the reviewers for their invaluable contributions to the reviewing process.

Zhaohui Li Hanlie Hong Guocheng Lv 

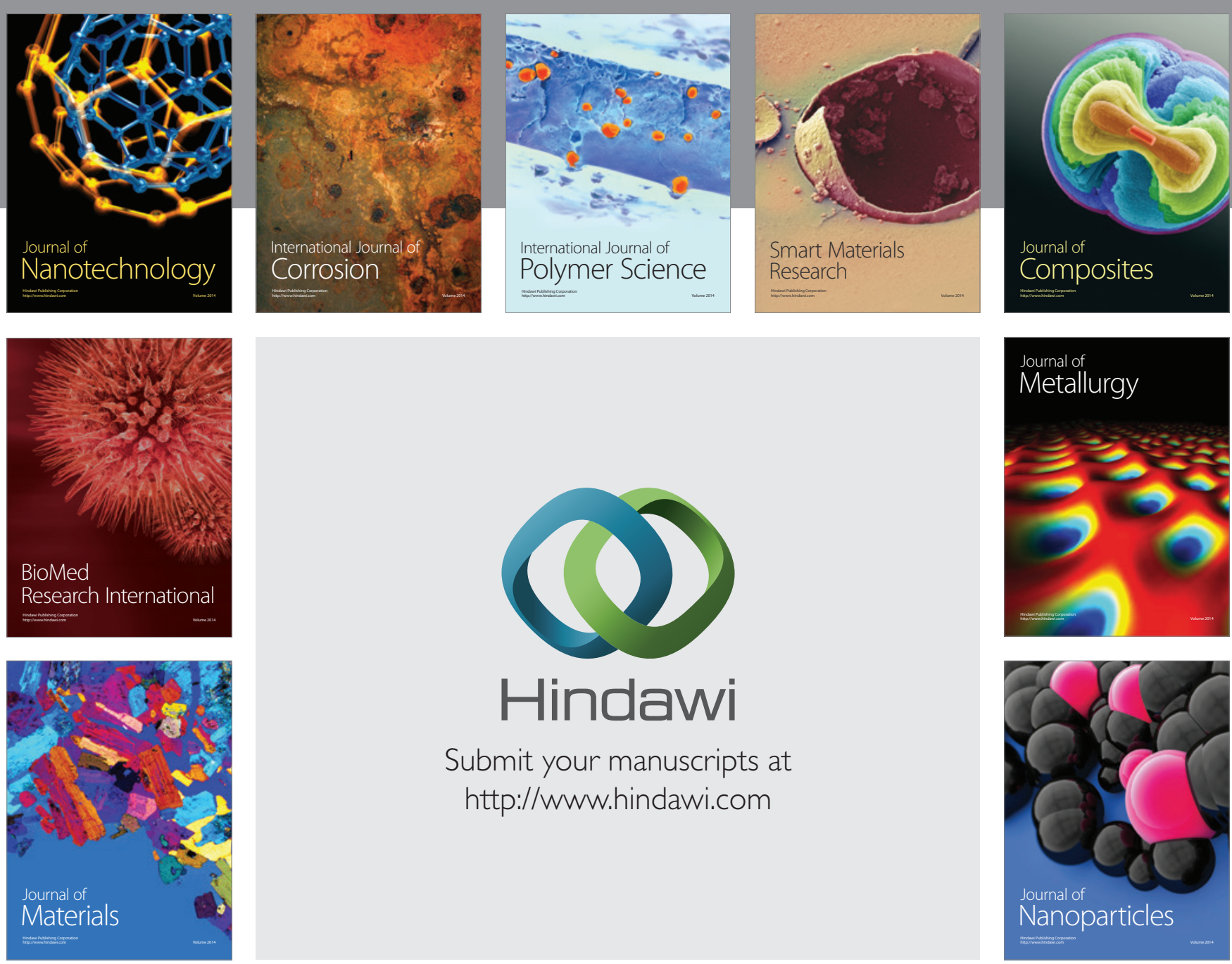

Submit your manuscripts at http://www.hindawi.com
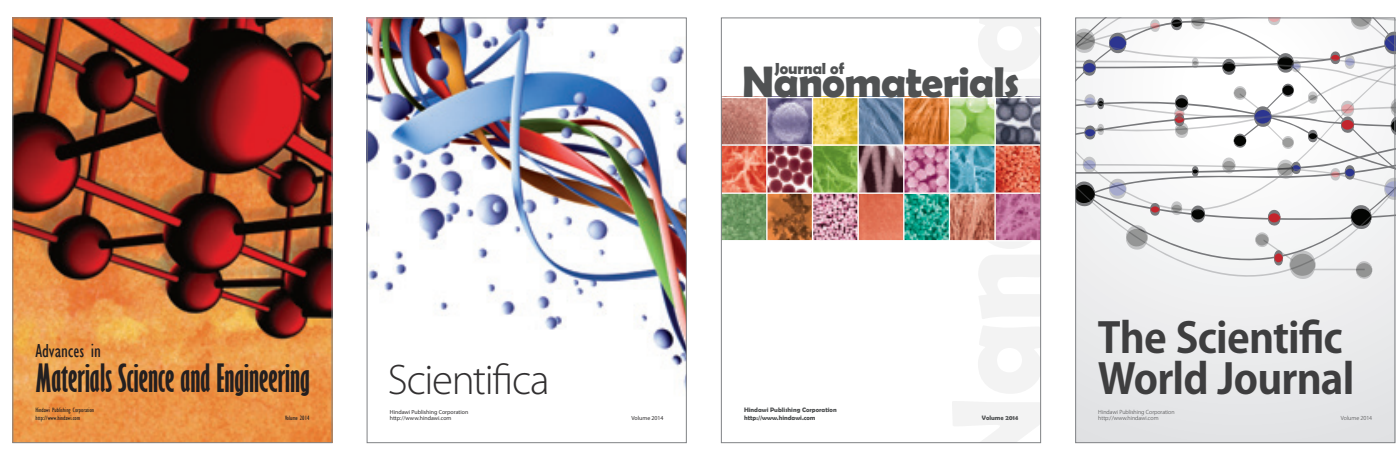

\section{The Scientific World Journal}
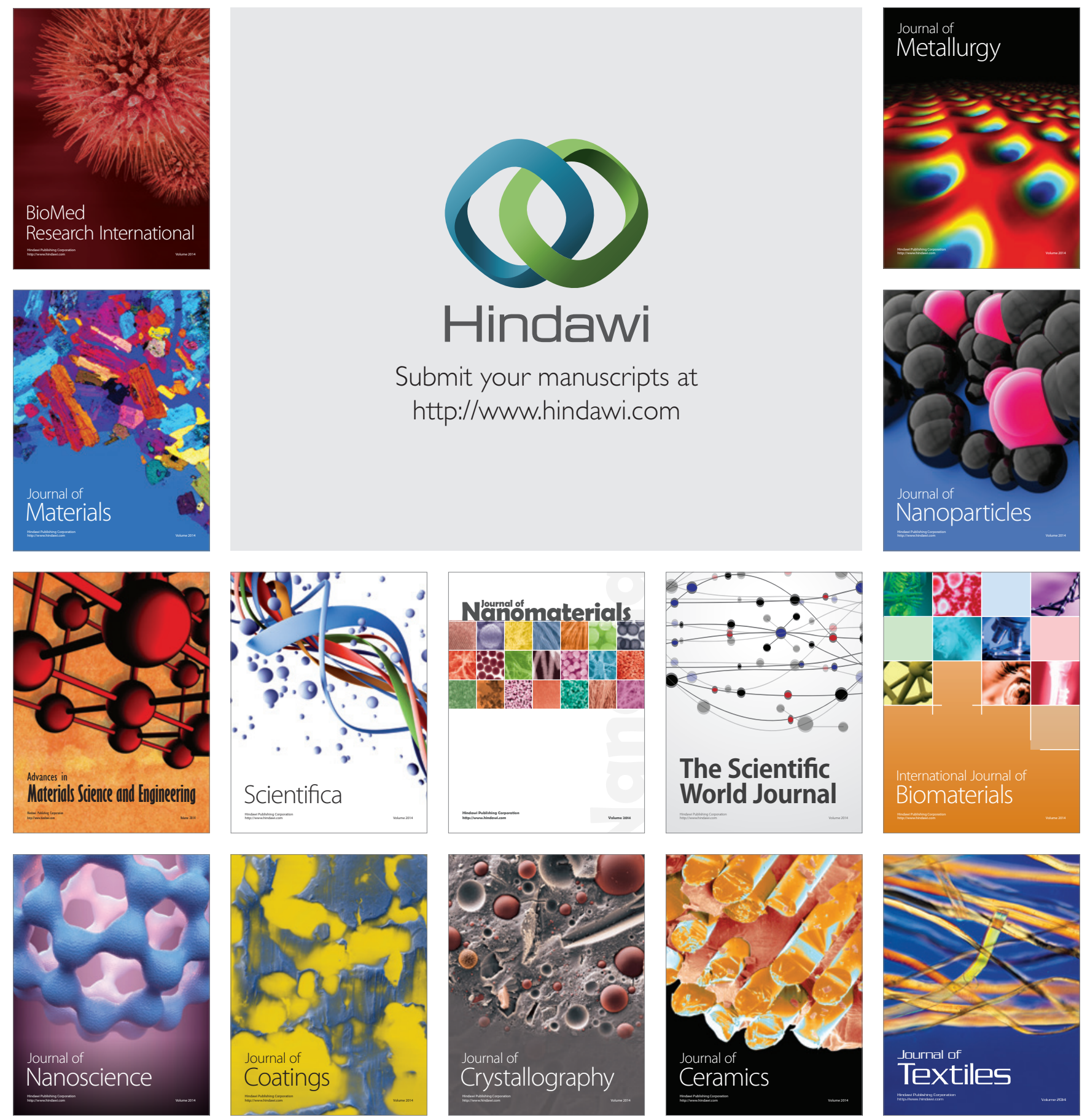